\title{
Rut Performance of In Situ Warm Mix Asphalt Overlays with Evotherm 3G in North Dakota
}

\author{
Mahdi Rezapour (1D) ${ }^{1}$ and Shaun S. Wulff ${ }^{2}$ \\ ${ }^{1}$ Department of Civil and Architectural Engineering, University of Wyoming, Office: EN 3084, 1000 E University Ave, \\ Dept. 3295, Laramie, WY 82071, USA \\ ${ }^{2}$ Department of Statistics, University of Wyoming, Office: Ross Hall 336, USA
}

Correspondence should be addressed to Mahdi Rezapour; mrezapou@uwyo.edu

Received 30 November 2018; Accepted 3 April 2019; Published 17 April 2019

Academic Editor: Kamran Iqbal

Copyright (C) 2019 Mahdi Rezapour and Shaun S. Wulff. This is an open access article distributed under the Creative Commons Attribution License, which permits unrestricted use, distribution, and reproduction in any medium, provided the original work is properly cited.

\begin{abstract}
As warm mix asphalt (WMA) pavements afford compaction at temperatures several dozen degrees lower than hot mix asphalt (HMA), the rate of cooling drops dramatically allowing paving to continue into colder weather. For this study, field samples from the Valley City project were collected after being in service (aged) for three years. The historical weather data during study period, 2011-2014, indicates that the temperature in Valley City dropped up to $-34^{\circ} \mathrm{C}$ in winter. Prior studies have noted the importance of studying the performance of asphalt in different environmental conditions, and with different additives. Therefore, this study was set forward to study rutting resistant of field WMA in one of the coldest regions in the US, which used Evotherm $3 \mathrm{G}$ as an additive. The research aimed to compare aged WMA rutting resistance, including Evotherm 3G, to that when the specimens were newly constructed. The Asphalt Pavement Analyzer (APA) was used to compare the rutting resistances of WMA and the control HMA. The results indicated that aged samples were more rut resistant than nonaged samples under wet and dry testing conditions. Also under wet and dry testing conditions, aged WMA samples exhibited lower rutting resistance than aged HMA samples. No interaction effects of aging and Evotherm $3 \mathrm{G}$ were found on the rutting resistance of asphalt. Addressing the issue of binder aging and its effects on the overall rut performance of pavements gives further insight into the utility of WMA overlays in cold weather regions such as North Dakota.
\end{abstract}

\section{Introduction}

Warm mix asphalt (WMA) is a technology that allows manufacturers of asphalt to lower the production and compaction temperature of asphalt mixtures by up to $100^{\circ} \mathrm{F}$. Recently, stringent environmental regulations have resulted in using WMA technologies. Reducing mixing and compaction temperatures induced reduction in fuel costs and emissions [1]. Apart from those benefits, WMA can facilitate longer haul distances and cool weather pavement [2].

Depending on the type of binder used, North American Hot Mix Asphalts (HMA) are generally heated to $300^{\circ} \mathrm{F}$. WMA technologies give the process and production the capability of reducing temperature without compromising the performance of the pavement [3]. However, a lower compaction temperature results in lower rutting resistance of asphalt mixes [4]. Reduced oxidation of the WMA binder is one of the reasons of reduced moisture and rutting resistance of WMA [5]. Rutting is one of the main causes of failure in pavement structures. Rutting is another term used for unrecoverable deformation caused by traffic loading which leads to lateral movement of pavement materials. As a result of this deformation or rutting distress, vehicles tend to be pulled to the rut depth.

A number of WMA formulae have been accepted by the asphalt industry such as Sasobit, Evotherm, and REVIX. Using a lower temperature during production and placement of WMA has important advantages. In the original type of Evotherm, the emulsion is produced using a chemical package designed to enhance adhesion, coating, and workability. Most of the water flashes off as steam when the additive is mixed with the aggregate [6]. Evotherm 3rd Generation (3G) 


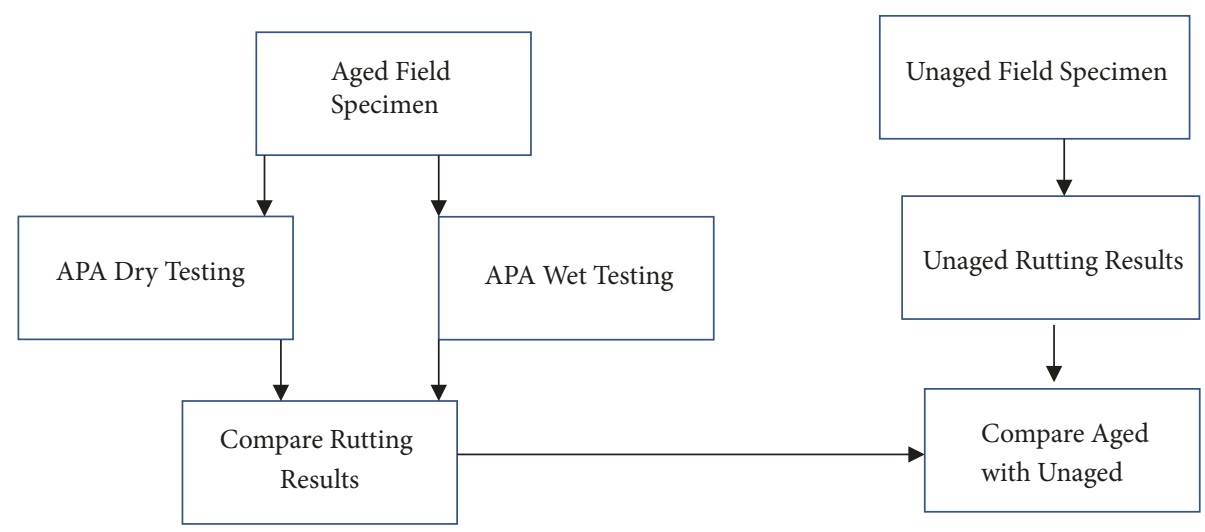

FIGURE 1: Flow chart for testing and analyzing the specimens.

is a water-free WMA which is easy and ready-to-use formula that allows application of asphalt at a temperature $60^{\circ}-90^{\circ} \mathrm{F}$ lower than traditional HMA.

However, rutting distress is the major concern in using WMA technology [7, 8]. A considerable amount of literature has been published on WMA rutting with different Evotherm technologies, but they have shown mixed results. A number of studies have reported decreased rutting of WMA with Evotherm. Hurley and Prowell measured rutting resistance of WMA with Evotherm using an asphalt paver analyzer (APA) [3]. They found that the addition of Evotherm did not statistically affect the rutting resistance of asphalt. Ghabchi et al. compared rutting resistance of WMA with Evotherm and HMA using the Hamburg wheel tracking (HWT) test [9]. The results revealed that the performance of WMA depends on the technology and the type of additive used, and WMA had lower and, in some cases, equal rutting resistance compared to HMA. Similarly, the effects of three types of WMA additives were investigated by $\mathrm{Du}$ and $\mathrm{Li}$ [10]. The test results indicated that Evotherm DAT improved rutting resistance of Hot Mix Asphalt. Prowell et al. investigated field performance of WMA by incorporating Evotherm. The rutting resistance carried out by the APA indicated that WMA had similar rutting resistance compared to HMA. Behl et al. conducted a study to evaluate aging characteristics of WMA binders [11]. The results indicated that Evotherm based WMA aged at lower temperature showed higher resistance to rutting to that of the control aged HMA. Syed et al. investigated the rutting performance of WMA with Evotherm and compared it with HMA [12]. The results indicated that WMA showed lower rut depth compared with HMA.

On the other hand, research by Sargand et al. indicated that mixtures with WMA have lower rutting resistance than HMA [13]. All types of WMA, with Evotherm, Sasobit, and Aspha-Min, had more rutting under rolling wheel loads than traditional HMA, with Evotherm having the highest rutting. A study was conducted by Wu et al. to investigate the performance of field aged WMA [14]. The results indicated that Evotherm binder was comparable with HMA binder after field aging. However, file aged HMA exhibits higher rutting resistance than Evotherm WMA. The importance of environmental conditions on the performance of WMA was investigated in the literature [15]. It was shown that the mechanical properties of WMA would be affected by climatic factors.

While few studies have been conducted to evaluate the rutting performance of WMA containing Evotherm 3G, in-field performance of WMA containing Evotherm $3 \mathrm{G}$ is scanty. Moreover, not much research evaluated the rutting resistance of in situ aged WMA with Evotherm 3G under the cold weather conditions, with performance grading (PG) 58-28, such as that in North Dakota, USA. This study was conducted to fulfill the following objectives:

The first objective is to evaluate and compare rut values of aged and unaged WMA specimens to HMA specimen for dry and wet conditions.

The second objective is to statistically analyze the effects of aging and additive (WMA and HMA) on rutting resistance.

\section{Methodology}

The samples were collected from overlays on the section near Valley City using Evotherm 3G as an additive on the North Dakota Department of Transportation (NDDOT) asphalt paving project. The historical weather data indicates that weather in Valley City dropped to $-34^{\circ} \mathrm{C}\left(-30^{\circ} \mathrm{F}\right)$, between 2011 and 2014. About 5 miles of this project was paved with WMA for the experimental section and about 5 miles of the project was the control section using binder type PG 58-28 for both sections. The location of the experimental part is from reference point (RP) 56.480 to RP 61.233 and the control part, HMA, is from RP 51.000 to RP 56.000. To fulfill the objectives of this study, the methods depicted in Figure 1 are taken.

In 2011, samples (Unaged) were collected by Suleiman and Mandal with the objective of evaluating rut resistance of NDDOT WMA overlays with respective HMA [16]. The purpose of that study was to compare rutting resistance of WMA with HMA under dry and wet conditions using the asphalt pavement analyzer (APA).

The samples used in this research for rutting comparison between WMA and HMA were provided by NDDOT. The WMA and HMA samples had the same traffic and environmental conditions. Similar binders and aggregates were also 
TABLE 1: Field core specimen identification.

\begin{tabular}{lcccr}
\hline Core Locations & Core Number & Quantity-EB & Quantity-WB & Type \\
\hline 54.500 & $1-4$ & 2 & 2 & HMA \\
\hline 55.000 & $5-8$ & 2 & 2 & HMA \\
\hline 55.500 & $9-12$ & 2 & 2 & HMA \\
\hline 56.000 & $13-16$ & 2 & 2 & HMA \\
\hline 57.329 & $17-20$ & 2 & 2 & WMA \\
\hline 58.939 & $21-24$ & 2 & 2 & WMA \\
\hline 59.548 & $25-28$ & 2 & WMA \\
\hline 60.170 & $29-32$ & 2 & WMA \\
\hline
\end{tabular}

TABLE 2: Average WMA and HMA temperature during different pavement process operations in ND.

\begin{tabular}{|c|c|c|c|c|c|}
\hline $\begin{array}{l}\text { Average WMA and } \\
\text { HMA } \\
\text { Temperature (F) }\end{array}$ & Windrow & $\begin{array}{l}\text { Behind } \\
\text { Paver }\end{array}$ & $\begin{array}{c}\text { Behind } \\
\text { Roller }\end{array}$ & $\begin{array}{l}\text { Behind } \\
\text { 2nd } \\
\text { Roller }\end{array}$ & $\begin{array}{l}\text { Behind } \\
\text { 3rd } \\
\text { Roller }\end{array}$ \\
\hline $\begin{array}{l}\text { SS-3-020(072)069 } \\
\text { WMA }\end{array}$ & 249 & 234 & 228 & 161 & 162 \\
\hline $\begin{array}{l}\text { SNH-3-281(093)128 } \\
\text { HMA }\end{array}$ & 283 & 273 & 250 & 224 & 165 \\
\hline
\end{tabular}

used in making the samples. The locations of core specimen are presented in Table 1.

Thirty-two specimens were chosen for APA rut testing, 16 of them for dry testing and 16 of them for wet testing. Sixteen HMA specimens were chosen in a similar manner to the WMA. The dimension of the specimen used in APA was 6 inches in diameter and 3 inches high $(15 \mathrm{~cm}$ in diameter and $7.5 \mathrm{~cm}$ high). A concrete saw was used to cut and prepare the specimens from the top to the depth of three inches, which is the required depth for APA rut testing.

For rutting evaluation under the wet condition, specimens were heated to $58^{\circ} \mathrm{C}$ for about 6 hours, which is in accordance with the PG grade of the binder used in the asphalt. For wet condition, specimens were immersed in the tank filled with water at the temperature of $58^{\circ} \mathrm{C}$. Similarly, for dry conditions, $58^{\circ} \mathrm{C}$ was chosen for the APA dry condition.

Prior to running the APA test, the specimens for dry conditioning were heated for 6 hours to $58^{\circ} \mathrm{C}$, which matched the high temperature of the PG grade 58-28 used in the project by NDDOT. This temperature would be maintained during the actual APA dry test. For wet conditioning, the specimens were placed in a $58^{\circ} \mathrm{C}$ water bath for 24 hours prior to the test. The same test preparation procedure was maintained for both HMA and WMA cases.

The Asphalt Pavement Analyzer (APA) was used to compare the rutting resistance of WMA with correspondent HMA. APA testing is based on AASHTO TP 63-03, which is the standard test method for determining rutting susceptibility of asphalt paving mixture using the APA. Testing time for rutting was about 2 hours which consisted of 8000 cycles. The wheel load applied in APA is $100 \mathrm{psi}(45 \mathrm{Kg})$ which was uniformly applied on the specimens [17]. The utilization of APA has been cost-effective, fast, and practical to use. A 3/4inch $(9.0 \mathrm{~mm})$ rutting was considered as failure criteria for this test.
The temperatures of pavement for both HMA and WMA at windrow, behind the paver, and behind different rollers in North Dakota are presented in Table 3. For the comparison, the temperature behind the roller was used as compacting temperatures for WMA and HMA. As can be seen from Table 2, the temperature difference in windrow was 34 while this difference behind 3rd roller was only 3 degrees. This could be an indication that the rate of cooling drops dramatically, which allows paving to continue into colder weather.

A total of 8 different types of asphalt mixes were considered in this study (See Table 3). These types include age (aged; unaged), temperature (warm; hot), and moisture (wet; dry). For each type of asphalt mixes, there were 8 samples. Some samples were lost in testing for the unaged category. As can be seen from the table, unaged dry warm mix asphalt (UDWMA) had the highest sample mean rut depth $(8.90 \mathrm{~mm})$ while aged dry hot mix asphalt (ADHMA) had the lowest sample mean $(4.45 \mathrm{~mm})$.

Two-way analysis of variance (ANOVA) was performed to analyze rutting depth. Separate analyses were conducted for each moisture level (wet; dry). Two-way ANOVA was used to assess main effects of age and temperature as well as the interaction effects of age and temperature on rutting depth. Let $i$ index age ( 0 years; 3 years), $j$ index temperature (warm; hot), and $\mathrm{k}$ index the sample. Then the statistical model has the form

$$
y \mathrm{ijk}=\mu+\alpha \mathrm{i}+\beta \mathrm{j}+(\alpha \beta) \mathrm{ij}+\mathrm{eijk},
$$

$\mu=$ overall population mean depth of rutting

$\alpha \mathrm{i}=$ main effect of age $\mathrm{i}$

$\beta \mathrm{j}=$ main effect of temperature $\mathrm{j}$

$(\alpha \beta) \mathrm{ij}=$ interaction effect of age $\mathrm{i}$ and temperature $\mathrm{j}$ 
TABLE 3: Sample means and sample standard deviations of samples according to combinations of age, moisture, and temperature.

\begin{tabular}{llll}
\hline Asphalt Sample & Number of samples & Mean & Standard Deviation \\
\hline Aged dry WMA & 8 & 7.04 & 2.08 \\
\hline Aged wet WMA & 8 & 6.33 & 0.58 \\
\hline Aged dry HMA & 8 & 4.45 & 0.98 \\
\hline Aged wet HMA & 8 & 5.13 & 0.65 \\
\hline Unaged dry WMA & 6 & 8.90 & 0.43 \\
\hline Unaged wet WMA & 6 & 8.57 & 0.74 \\
\hline Unaged dry HMA & 6 & 7.92 & 0.68 \\
\hline Unaged wet HMA & 6 & 6.62 & 1.03 \\
\hline
\end{tabular}

TABLE 4: ANOVA table for rut depth under wet conditions and dry conditions.

\begin{tabular}{|c|c|c|c|c|c|}
\hline \multicolumn{6}{|c|}{ Dry Mix } \\
\hline Factors & $\mathrm{DF}$ & Sum of squares & Mean Square & F-value & $p$-value \\
\hline temp & 1 & 21.78 & 21.78 & 11.35 & 0.0025 \\
\hline age & 1 & 48.84 & 48.84 & 25.45 & $<0.0001$ \\
\hline temp*age & 1 & 4.45 & 4.45 & 2.32 & 0.1409 \\
\hline error & 24 & 46.05 & 1.92 & & \\
\hline Total & 27 & 124.53 & & & \\
\hline $\mathrm{R}^{2}$ & & 0.63 & & & \\
\hline \multicolumn{6}{|c|}{ Wet Mix } \\
\hline Factors & $\mathrm{DF}$ & Sum of squares & Mean Square & F-value & $p$-value \\
\hline temp & 1 & 17.04 & 17.04 & 25.96 & $<0.0001$ \\
\hline age & 1 & 23.99 & 23.99 & 36.55 & $<0.0001$ \\
\hline temp $*$ age & 1 & 0.96 & 0.96 & 1.46 & 0.2388 \\
\hline Error & 24 & 15.75 & 0.66 & & \\
\hline Total & 27 & 56.93 & & & \\
\hline $\mathrm{R}^{2}$ & & 0.72 & & & \\
\hline
\end{tabular}

eijk = experimental error for sample $\mathrm{k}$ with age $\mathrm{i}$ and temperature $\mathrm{j}$

The analysis of the model was done using the glm procedure in SAS 9.4 (SAS Institute, 2014).

\section{Results}

Table 4 presents the two-way ANOVA results for examining the effects of age and temperature on rut depth. The ANOVA test was conducted separately for wet and dry conditions. The effects were declared to be non-zero when the $\mathrm{p}$ value was less than the specified significance level of 0.05 . Since there were an unequal number of samples across age, the sum of squares was based upon weighted squares of means or Type III Sums of Squares in SAS GLM [18].

For the dry mix conditions, the interaction effects were all declared to be 0 ( $p$ value $=0.1409)$. However, there were nonzero effects due to temperature $(\mathrm{p}$ value $=0.0025)$ and age $(\mathrm{p}$ value $<0.0001)$.

Similar conclusions for the effects on rut depth were found for rutting depth with wet testing conditions. The interaction effects were declared to be zero ( $p$ value $=0.2388$ ). The main effects of temperature ( $p$ value $<0.0001)$ and age $(p$ value $<0.0001)$ were declared to be non-zero.
Since there are no interaction effects involving temperature and age, the associated marginal means are of particular interest. The least squares means, standard errors, and test of equality of the marginal means are presented in Table 5 for both the dry mix and wet mix conditions. The $\mathrm{p}$ values associated with the test of equal marginal means are the same as the test of non-zero main effects in Table 4 since there are only two levels of these factors. Under both conditions, the marginal mean rutting depth is smaller for the hot mix (HMA) than for the warm mix (WMA). The marginal mean rutting depth is also smaller for aged asphalt compared to unaged asphalt for both conditions.

The previous test results were based upon assumptions on the model errors (eijk). These assumptions include independence, normality, and equal variance. The assumptions can be evaluated using studentized residuals.

First, the residuals were plotted in Figure 2 from the model fit for wet mix. The plot of studentized residuals versus predicted values illustrated random scatter of the residuals about 0 with fairly equal spread. A Levene test of equal variance across the predicted values did not indicate a violation of the homogeneity of variance assumption on the model errors $(\mathrm{F} 3,24=1.56$; $\mathrm{p}$ value $=0.2245)$. The normality plot of the studentized residuals showed the residuals lying 

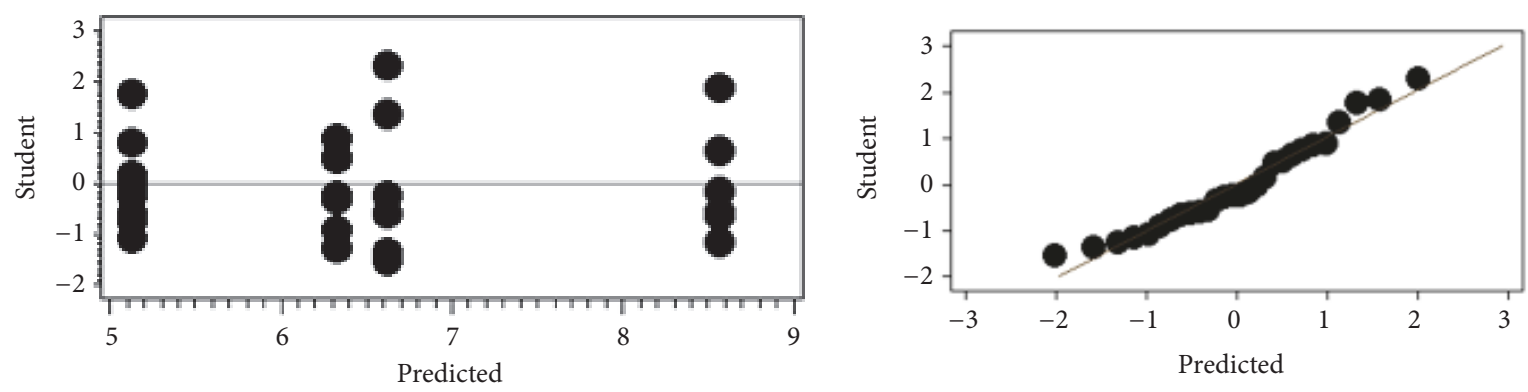

FIGURE 2: Plots of studentized residuals versus predicted values and versus normal quantiles for wet mix.
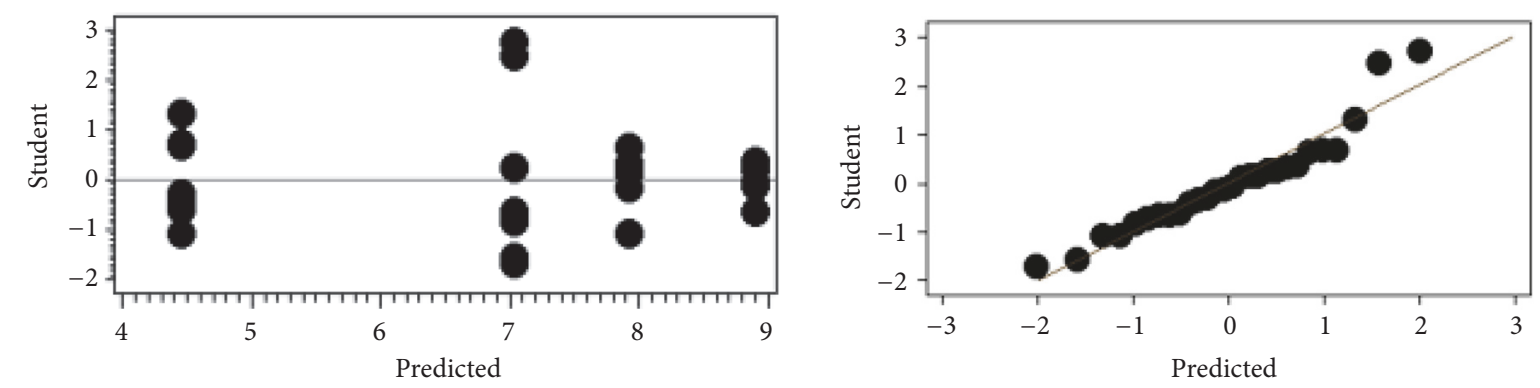

FIGURE 3: Plots of studentized residuals versus predicted values and versus normal quantiles for dry mix.

TABLE 5: Least squares means and standard errors for age and temperature levels for the dry mix condition and for the wet mix condition.

\begin{tabular}{lc}
\hline Dry Mix & Rutting depth $(\mathrm{mm}) \pm \mathrm{SE}$ \\
\hline Temperature & $6.18 \pm 0.37$ \\
Hot & $7.97 \pm 0.37$ \\
Warm & 0.0025 \\
P-value & \\
Age & $8.41 \pm 0.40$ \\
0 yrs & $5.74 \pm 0.34$ \\
3 yrs & $<0.0001$ \\
P-value & \\
Wet mix & \\
Temperature & \\
Hot & $5.87 \pm 0.22$ \\
Warm & $7.45 \pm 0.22$ \\
P-value & $<0.0001$ \\
Age & \\
0 yrs & $7.60 \pm 0.23$ \\
3 yrs & $5.73 \pm 0.20$ \\
P-value & $<0.0001$ \\
\hline
\end{tabular}

close to the theoretical normal line. A Wilk-Shapiro test of normality on the model errors did not indicate problems with the normality assumptions $(\mathrm{W}=0.9530$; $\mathrm{p}$ value $=0.2349$ )

The residuals were also plotted in Figure 3 from the model fit for dry mix. The plot of studentized residuals versus predicted values illustrated random scatter of the residuals about 0 , but with unequal spread. This appeared to be due to the studentized residuals near a predicted value of 7. A Levene test of equal variance across the predicted values confirmed this observation $(\mathrm{F} 3,24=3.96$; $\mathrm{p}$ value $=0.0199)$. The normality plot of the studentized residuals showed the residuals lying close to the theoretical normal line, except for the largest two studentized residuals. A Wilk-Shapiro test of normality on the model errors did suggest problems with the assumptions of normality due to these residuals ( $\mathrm{W}=$ $0.9261 ; \mathrm{p}$ value $=0.0492$ ). Thus, the assumptions on the model errors appear to not be met due to the first two samples which consist of the largest observed rut depth $(10.57,10.24)$. In fact, these were the only observations in the dataset that exceeded 10.

If these samples were removed from the analysis, then the assumptions on the model errors appeared to be met. The Levene test of equal variance across the predicted values did not indicate a violation of the homogeneity of variance assumption on the model errors (F3,22 $=1.24$; $\mathrm{p}$ value $=$ 0.3175). The Wilk-Shapiro test of normality on the model errors also did not indicate problems with the normality assumptions $(\mathrm{W}=0.9781 ; \mathrm{p}$ value $=0.8320)$. The two-way ANOVA was refit without samples 1 and 2 and the results are shown in Table 6. The total and residual sum of squares decreased as a result of removing these extreme observations. Otherwise, the results and conclusions do not change. The interaction effects would be declared to be zero, and the main effects due to temperature and due to age would be declared to be non-zero.

3.1. Summary and Conclusions. It is a fact that the properties of binder and WMA additive can impact the properties of asphalt mixture. So, a better understanding of the 
TABLE 6: ANOVA table for rut depth for dry mix without samples 1 and 2.

\begin{tabular}{|c|c|c|c|c|c|}
\hline \multicolumn{6}{|c|}{ Dry Mix } \\
\hline Factors & DF & Sum of squares & Mean Square & F-value & $p$-value \\
\hline temp & 1 & 9.53 & 9.53 & 13.35 & 0.0014 \\
\hline age & 1 & 66.79 & 66.79 & 93.50 & $<0.0001$ \\
\hline temp*age & 1 & 0.38 & 0.38 & 0.53 & 0.4733 \\
\hline error & 22 & 15.71 & 0.71 & & \\
\hline total & 25 & 97.79 & & & \\
\hline $\mathrm{R}^{2}$ & & 0.84 & & & \\
\hline
\end{tabular}

performance of WMA with different asphalt and additives can help to implement this technology more successfully. Moreover, most of the studies so far are based on the either short-term field performance of WMA pavement or lab testing. The literature lacks rutting filed performance of WMA with Evotherm 3G in climate conditions such as North Dakota. Therefore, the main goal of this study was to obtain a better understanding of the rutting resistance of WMA with Evotherm $3 \mathrm{G}$ in this state.

APA testing machine on PG 58-28 Evotherm 3G was carried out to investigate the rutting resistance of asphalt samples collected in cold weather climates such as North Dakota. Comparisons were made across pavement mix temperature (WMA and HMA) under both dry and wet testing conditions. The age of the samples (unaged and aged) was also compared. Unaged rut data from a previous study involving the same paving project, Suleiman and Mandal, were compared with the aged rut results of this study [16].

Two-way ANOVA was used to statistically assess the effects of temperature and age. This study reached the following conclusions:

(1) Regardless of moisture conditions, there were no nonzero interaction effects involving age and temperature.

(2) Under both dry and wet conditions, aged samples (3 years after construction) had lower mean rut resistance than unaged samples (those immediately after construction).

(3) Under dry conditions and after 3 years, the estimated mean reduction in rut depth was $31.7 \%$.

(4) Under wet conditions and after 3 years, the estimated mean reduction in rut depth was $24.6 \%$.

(5) The rut depth comparisons between aged WMA and HMA under dry and wet conditions revealed that WMA rut resistance is inferior to HMA.

(6) Under dry conditions, the estimated mean difference in rut depth, between aged and unaged samples, was $22.4 \%$.

(7) Under wet conditions, the estimated mean difference in rut depth, between aged and unaged samples, was $21.2 \%$.

The results of this study can be applied to the rutting resistance of WMA with Evotherm in similar weather climates.
Furthermore, more studies are needed to confirm the results obtained by this study.

3.2. Recommendation. This study provides a realistic representation of the long-term in situ rutting resistance of WMA with Evotherm 3G. In addition, this research has thrown up many questions in need of further investigation about WMA with Evotherm 3G. It is recommended that further research be undertaken in the following areas:

More research is needed to investigate and address the low rutting resistance of WMA with Evotherm 3G.

The future research could assess the longer term resistance of WMA with Evotherm.

\section{Data Availability}

The data used to support the findings of this study are available from the corresponding author upon request.

\section{Conflicts of Interest}

The authors declare that they have no conflicts of interest.

\section{References}

[1] G. C. Hurley and B. D. Prowell, "Evaluation of Aspha-Min Zeolite for use in Warm Mix Asphalt," NCAT Report 05-04, 2005.

[2] J. A. D’Angelo, E. E. Harm, J. C. Bartoszek et al., "Warm-Mix Asphalt: European Practice," 2008.

[3] G. C. Hurley and B. D. Prowell, "Evaluation of Evotherm for use in Warm Mix Asphalt," NCAT Report, 2006.

[4] W. Zhao, F. Xiao, S. N. Amirkhanian, and B. J. Putman, "Characterization of rutting performance of warm additive modified asphalt mixtures," Construction and Building Materials, vol. 31, pp. 265-272, 2012.

[5] R. West, C. Rodezno, G. Julian, and B. Prowell, "Engineering Properties and Field Performance of Warm Mix Asphalt Technologies," 2014, NCHRP 9-47 Final Rep.

[6] B. Prowell, Warm Mix Asphalt, the International Technology Scanning Program Summary Report, American Trade Initiatives, USA, 2007.

[7] J. D. Doyle and I. L. Howard, "Rutting and moisture damage resistance of high reclaimed asphalt pavement warm mixed asphalt: Loaded wheel tracking vs. conventional methods," Road Materials and Pavement Design, vol. 14, pp. 148-172, 2013. 
[8] A. Kavussi and L. Hashemian, "Laboratory evaluation of moisture damage and rutting potential of WMA foam mixes," International Journal of Pavement Engineering, vol. 13, no. 5, pp. 415-423, 2012.

[9] R. Ghabchi, D. Singh, and M. Zaman, "Laboratory evaluation of stiffness, low-temperature cracking, rutting, moisture damage, and fatigue performance of WMA mixes," Road Materials and Pavement Design, pp. 1-24, 2015.

[10] S.-W. Du and S. Li, "The effect of different warm additives on performance properties of HMA," Applied Mechanics and Materials, vol. 178-181, pp. 1369-1372, 2012.

[11] A. Behl and S. Chandra, "Aging characteristics of warm-mix asphalt binders," Journal of Materials in Civil Engineering, vol. 29, no. 10, Article ID 04017155, 2017.

[12] I. Syed, M. A. Hasan, and R. A. Tarefder, "Investigation of rutting performance of different warm mix asphalt (WMA) Mixtures," International Journal, vol. 14, no. 45, pp. 116-123, 2018.

[13] S. M. Sargand, W. F. Edwards, and J. Bendana, "Testing of Perpetual Pavement with Warm Asphalt Concrete Surface Mixes in the Ohio APLF," 2008.

[14] S. Wu, W. Zhang, S. Shen, X. Li, B. Muhunthan, and L. N. Mohammad, "Field-aged asphalt binder performance evaluation for Evotherm warm mix asphalt: Comparisons with hot mix asphalt," Construction and Building Materials, vol. 156, pp. 574-583, 2017.

[15] Y. Luo, Z. Zhang, G. Cheng, and K. Zhang, "The deterioration and performance improvement of long-term mechanical properties of warm-mix asphalt mixtures under special environmental conditions," Construction and Building Materials, vol. 135, pp. 622-631, 2017.

[16] N. Suleiman and S. Mandal, "Assessing the Rut Performance of Warm Mixes in North Dakota," 2014.

[17] S. Pirabarooban, M. Zaman, and R. A. Tarefder, Evaluation of Rutting Potential in Asphalt Mixes using Finite Element Modeling, 2003.

[18] R. O. O. Kuehl, Designs of Experiments: Statistical Principles of Research Design and Analysis, Duxbury Press, 2000. 


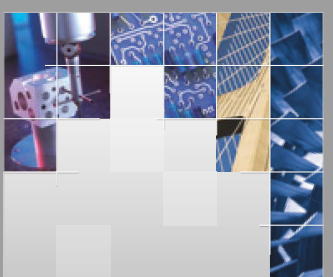

\section{Enfincering}
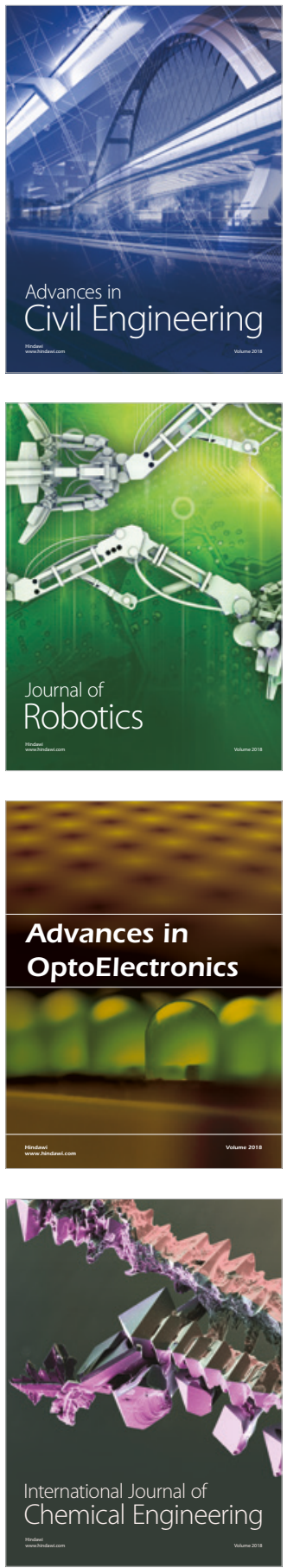

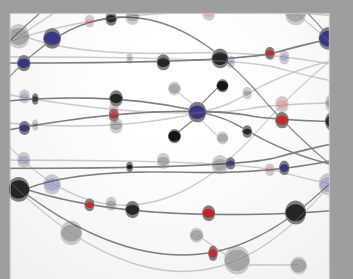

\section{Rotating \\ Machinery}

The Scientific World Journal

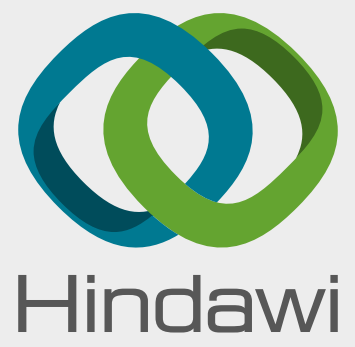

Submit your manuscripts at

www.hindawi.com
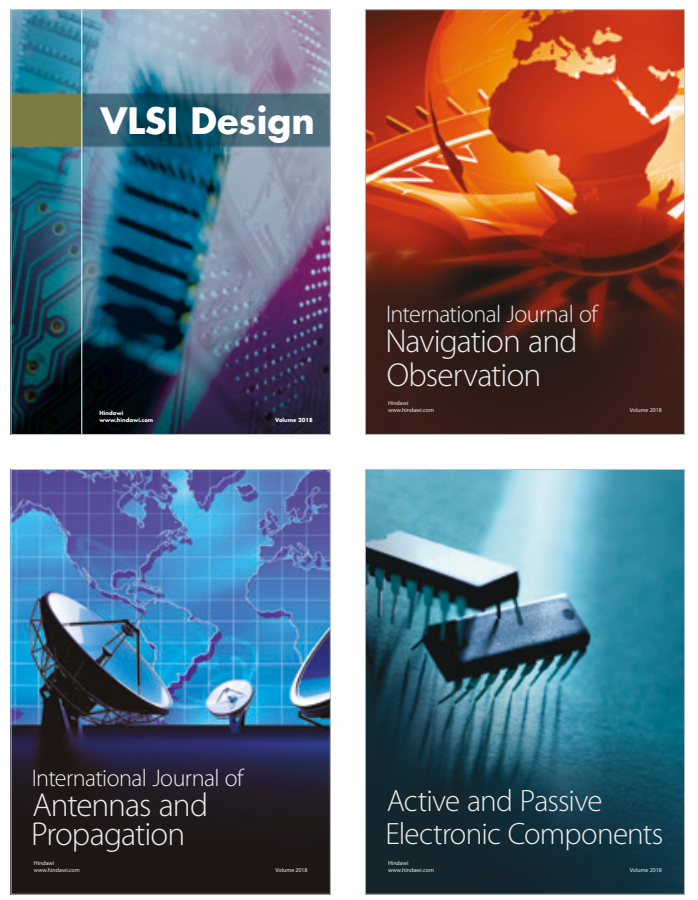
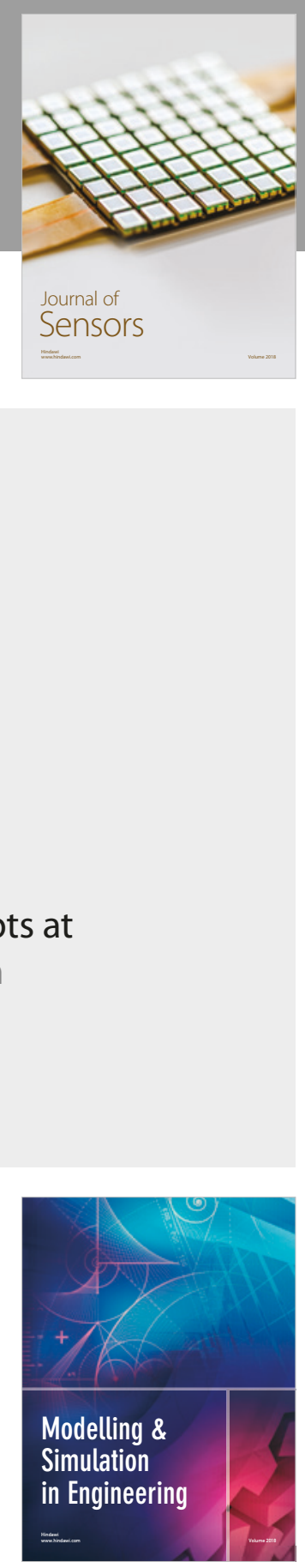

\section{Advances \\ Multimedia}
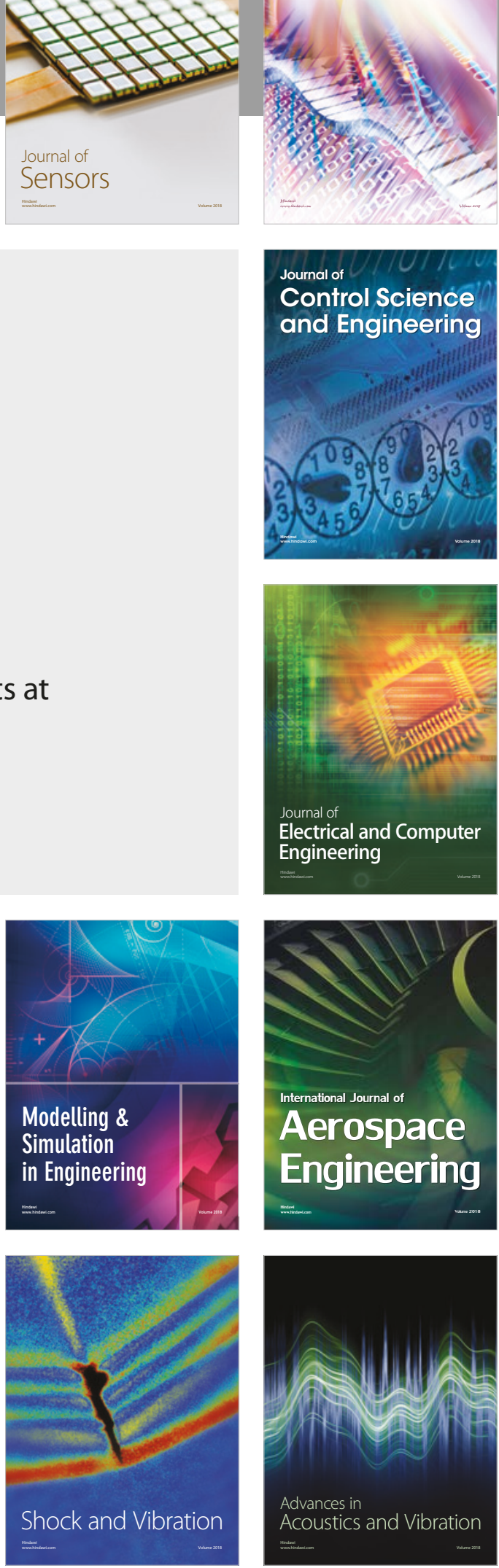